\title{
LOS RIESGOS DEL OCIO Y EL OCIO COMO RIESGO: DOS MARCOS METAFÍSICOS PARA CONCEPTUAR EL OCIO
}

Íñigo Ongay de Felipe

Facultad de Filosofía de León. León-Guanajuato. México

http://dx.doi.org/10.5209/NOMA.55043

\begin{abstract}
Resumen: Se propone un análisis del rótulo, académica y mundanamente exitoso, "Los riesgos del ocio" según el doble sentido - objetivo o subjetivo- del genitivo. Para ello se sugerirá la distinción entre una concepción del ocio como un "valor" que pueda a su vez verse comprometido por conjuntos - más o menos precisos o más o menos confusos- de factores amenazantes sean estos de orden social, económico, político, etc ( un punto de vista creemos que presupuesto en la concepción del "ocio" como fáctor valioso" de "desarrollo personal") y una visión del ocio según la cual este mismo tendería a contemplarse como una amenaza ( y por tanto , un "contra-valor") respecto de otros factores a los que ahora se propenderá a concebir como "valiosos". Nos parece que una tal distinción ilustra el tránsito histórico que separaría dos formas incompatibles de "pensar el ocio", a saber: aquella que en la dirección del pensamiento teológico luterano tenderá a ver el ocio como un riesgo y aun una amenaza frente a la salud espiritual del hombre ( aunque como se verá algunas corrientes de la teología moral católica tampoco se mantuvieron enteramente al margen de semejante conceptualización) y aquella que, por el contrario, promoverá una comprensión del ocio ( particularmente en sus versiones más "valiosas" como ocio "cultural", pero también como ocio "deportivo", etc) en tanto que factor esencialmente engranado en dicha "salvación" (entendida ahora a título de "desarrollo personal" o de "autorrealización") . Con objeto de dar cuenta de dicho tránsito haremos uso de la hipótesis del filósofo español Gustavo Bueno según la cual "el reino medieval de la gracia" queda transformado internamente en la modernidad, en el "reino de la cultura". Concluiremos del modo siguiente: sin perjuicio de que ambas concepciones resulten desde luego plenariamente incompatibles entre sí, ello no obsta para que las dos respiren en la misma atmósfera "soteriológica" y "metafísica" de partida.

Palabras clave: Ocio, cultura, gracia, salvación, metafísica.
\end{abstract}

Abstract: Thisarticleoffersananalysis of a theheading "thethreats of leisure" which has provenhighlysuccessfulbothacademically and in a more mundanesense. I analyzethisheadingbyexploringthesubjective and objectivesensesthatit can be accordedwithgrammatically. Takingthesetwosenses as a point of departure, I distinguish a conception of thenotion of leisure as a positive valuethat can eventually be threatenedby a set of social, economicalorpoliticalfactors, fromanotheraccount of the concept, accordingtowhichitisleisureitselfthat sto be regarded as a threatenonothervalues. Such a distinctionexemplifies a transit in thehistory of thoughtfrom a doctrine of leisure as a threatenjeopardizinghuman's Spiritual Health (somethingthatLutherantheology, butalsocuriouslyenoughsometrends in RomanCatholictheologicalthinking, wouldalwayssustain) toanotherverydifferentconceptionwhichviewsleisure ( particularlyinterpreted as cultural or sport leisure) as a factor positivelyintertwinedwiththeprocess of human salvationwhenunderstood as personal development and self-realization. Tothisend, I will use onethesisput forward by Gustavo Bueno, namely: theRealm of Grace in the medieval account of theworldgets in Modern Times 
transformedintothemetaphysicalnotion of Culture. Itwill be shown in conclusionthatevenifthesetwoconceptions are to be sureabsolutely incompatible withoneanother, both share theverysame set of soteriological and metaphysicalassumptions .

Key Words: Leisure, culture, grace, salvation, methaphysics.

\section{Introducción: sobre el dúplice sentido del enunciado titular.}

Nuestro objetivo es proponer, ya sea someramente, las líneas necesarias y suficientes para el análisis de dos grandes marcos de conceptualización de los fenómenos del ocio. Sin perjuicio de que con arreglo a sus contenidos (por así decir semánticos en el sentido de Charles Morris) respectivos, dichas conceptualizaciones se presenten ciertamente como marcos teóricos de construcción de la Idea de ocio no sólo diferentes sino incompatibles y aun diametralmente opuestos entre sí, y ello justamente por cuanto una representaría la negación plenaria de la otra, creemos, que la situación que una tal incompatibilidad plantea (genuinamente dialéctica) obedece a la oposición entre dos formas de concebir el ocio que respecto a su "género literario" ( esto es, sintácticamente) coincidirían en adoptar un formato propiamente metafísico. Según esto, la oposición entre ambos marcos, que aquí comenzamos por reconocer de plano, y ello frente a toda tentativa de identificarlos, se dibujaría en un terreno que en manera alguna mantendría un signo "científico-positivo" - sin perjuicio de las pretensiones que en este sentido pudiera mantener una de las conceptualizacionesen liza a las que nos referimos- aunque tampoco simplemente "mitológico", "ideológico" o "teológico-dogmático", en tanto en cuanto al menos, las ideas mismas removidas en las respectivas interpretaciones de los fenómenos de referencia (ideas tales como puedan serlo la de "humanidad" o la de "desarrollo" pero también la de "gracia", "cultura", "valor", "riesgo", "felicidad", etc) aparecerían como un conglomerado de nociones muy ceñido a los límites tradicionales de la racionalidad metafísica. Advertiremos asimismo que un tal diagnóstico no queremos plantearlo aquí tanto en un sentido meramente descalificador cuanto, precisamente, en una dirección crítico-clasificatoria tendente a "calificar" gnoseológicamente el alcance de tales marcos doctrinales.

Comencemos sin embargo, por sondear mínimamente el enunciado titular. El rótulo "Los riesgos del ocio", cuya presencia tanto académica como mundana ha venido incrementándose recientemente según se advierte por ejemplo en el enunciado titular del congreso Ociogune celebrado en Bilbao en junio de 2016, puede, a la manera de otros enunciados gramaticalmente análogos - esto es, aquellos caracterizados principalmente por la presencia del genitivo- ser 
interpretados en dos sentidos muy diferentes. Los gramáticos tradicionales daban cuenta de la diferencia mediante la apelación a la distinción general entre un sentido subjetivo y un sentido objetivo del genitivo.

Así por ejemplo, cuando alguien ( por hipótesis hablando desde la plataforma de la Roma imperial en las fases terminales de su desenvolvimiento histórico) se refiere al temor de Roma, una tal locución podrá sin duda recorrerse léxico-semánticamente en dos direcciones dualmente diferenciadas que sin embargo se darían al mismo tiempo como entreveradas entre sí a través del propio sintagma de referencia. Unas veces se dirá ( sobre todo si el hablante es un vándalo, un anglo, un sajón o un alamán) el temor de Roma referirá según el sentido objetivo del genitivo, al temor que la ciudad eterna y su potencia política de alcance imperial provocaría entre esas mismas poblaciones "bárbaras" situadas extra muros a los propios limes del Imperio. Otra veces, por el contrario, dicho temor, visto ahora según el sentido subjetivo del genitivo, se entenderá como un atributo, digamos psicológico, de la propia Roma, como un temor por ejemplo, muy singularmente instanciado entre aquellos de sus ciudadanos que pudieron asistir en torno al siglo $\vee$ a las penetraciones de las tribus bárbaras al final de lo que los historiadores conocen como la edad antigua.

Nos parece que un rótulo como pueda serlo "los riesgos del ocio" resulta susceptible de ser leído en dos direcciones análogas. De esta manera, cuando procedamos según el sentido objetivo del genitivo involucrado en el sintagma, el ocio podrá propender a entenderse como un conjunto de fenómenos polarizados axiológicamente de modo ponderativo o meliorativo; esto es como una realidad o una dimensión de la experiencia humana que quepa reconocer como valiosa en la dirección de la teoría axiológica defendida a comienzos del siglo XX por algunas de las direcciones de la filosofía idealista alemana ( Hartman, 1959) ( Scheler, 1948). Dichas tonalidades axiológicas positivas, que muchas veces tenderán a situarse más en unas variedades de ocio que en otras ( por ejemplo , y muy señaladamente ,en el "ocio cultural", pero también en el "ocio deportivo" o en el "solidario", en el "humanista", etc con preferencia al "ocio de botellón, "al ocio de discoteca" o al "ocio del consumo de opiáceos o drogas psicodélicas") sin embargo, se entenderán como susceptibles de quedar comprometidas por terceros fenómenos de muy diverso orden ( por caso: económicos, o sociales o políticos) que quepa consignar como "amenazas" o "riesgos" respecto de dichas variedades del "ocio valioso". Así, por ejemplo, la rapacidad económica del capitalismo neoliberal $O$, a sensu contrario desde premisas liberales, la expansión descontrolada del control centralizado por parte de un estado con pretensiones autoritarias o aun totalitarias podrán concebirse como 
factores (riesgos del ocio en el sentido objetivo del genitivo) capaces de amenazar hasta hacerlas desaparecer las dimensiones más enriquecedoras del ocio como factor de desarrollo humano.

Por otro lado, procediendo ahora a leer el sintagma de referencia a la luz del sentido objetivo del genitivo, el ocio mismo en cuanto fenómeno o conjunto de fenómenos llegará a adoptar una coloración axiológica sombría o negativa dotada de la suficiente virulencia como para amenazar o malograr otras realidades que serán ahora las interpretadas como valiosas.

Nos parece que estos dos sentidos del rótulo titular se coordinan de una manera excepcionalmente próxima a escala denotativa- salva veritatecon otros tántos marcos de conceptualización referidos la idea de ocio. Veámoslo.

\section{Los riesgos del ocio valioso.}

Comencemos por desbrozar el marco de conceptualización que se plegaría según lo dicho, al alcance objetivo del genitivo. De acuerdo a esta concepción, el ocio - o al menos algunas variantes específicas del mismo -sin perjuicio de que muchas veces el constitutivo formal de estas variantes tienda a darse simplemente por supuesto- comparece como una dimensión de la vida humana que, justamente en razón de su interconexión esencial respecto de otras ideas ( por ejemplo de la idea de felicidad pero también de la de cultura o de la de realización o auto-realización en el sentido de la psicología humanista, etc), merecería una atención preferencial por parte de psicólogos, sociólogos o educadores sociales. Esta atención iría dirigida sin duda a promover su cultivo en tanto que ocio valioso( Cuenca, 2014) por parte de los individuos de las sociedades del presente, y ello desde el momento en que tales actividades ( el disfrute de las artes, la práctica de los deportes o la colaboración con campañas solidarias o humanistas) pueden, según se constatará por vía empírica una y otra vez, erigirse en factores de desarrollo humano (Cuenca, 2014), autorealización (Goldstein, 1934) (Maslow, 1998) resiliencia familiar ( Navajas y Balsells, 2013) o aun en auténticos fundamentos de la felicidad de los hombres en el sentido del modelo eudemonista de la vida del sabio planteada por Aristóteles y que a su manera resuena, descontados desde luego sus componentes más característicamente teoréticoespeculativos, en doctrinas estoicas del ocio como la de Séneca ( Séneca, 2010).

Ahora bien, es lo cierto asimismo que unos tales componentes benéficos del ocio, definidos según se ve en un terreno prominentemente psicosocial, podrán verse amenazados e incluso- en el límite de esta amenaza- suprimidos de raíz por terceras realidades que ahora, y en buena dialéctica axiológica, comenzarán a poder contemplarse como 
"contra-valores". Estas realidades conforman un conjunto realmente muy tupido de factores de muy diversa índole. Algunas veces, tales amenazas mantendrán un rasante impersonal de signo cósmico o biológico ( singularmente en nuestros días de orden climatológico pongamos por caso) ( Madrid, 2010), aunque principalmente se recortarán sobre un horizonte más proporcionado a las ciencias humanas. Acaso muy señaladamente, este horizonte adquiere en el presente un alcance social, económico, ético, moral o político. De esta manera por ejemplo, en muchas ocasiones se tiende a asumir que el hiper-desarrollo económico capitalista, en lo que tiene de colonización del espacio público, promueve una desnaturalización del ocio que lo privaría de sus potencialidades valiosas cara al desarrollo humano. Desde otras coordenadas ( que haríamos coincidir en este punto con las premisas de la tradición liberal o libertaria) será más bien la pujanza de los estados nación con sus mecanismos coercitivos frente al individuo y su libertad de elección la que amenazará con asfixiar terminantemente las dimensiones más característicamente "autorealizadoras" de las actividades de ocio valioso en cuanto que estas deban en todo caso contemplarse como interna, esencialmente dependientes de la libertad de pensamiento o de expresión. La literatura científica más solvente abunda suficientemente en análisis muy precisos de los dinamismos sociales y psicológicos de tales riesgos así como de su incidencia comparativa en las diferentes sociedades de nuestro entorno con lo que, suponemos, sería en exceso prolijo por nuestra parte, desarrollar aquí esta temática sin perjuicio de su evidente interés para los asuntos de los que nos ocupamos.

\section{El ocio como riesgo.}

Recorramos ahora el rótulo titular "Los riesgos del ocio" en la dirección del genitivo subjetivo. Según ésta, la misma noción de ocio así como la abigarradísima serie de fenómenos que puedan asociarse a esta idea, propenderán a recibir una carga axiológica de orientación eminentemente negativa : el ocio, incluso en sus dimensiones "culturales" "deportivas", "solidarias" y "humanistas" ( y ello por no referirnos desde luego a otras variedades mucho menos nobles al parecer: el ocio de botellón o el ocio de discoteca o el ocio de consumo de sustancias estupefacientes por razones lúdicas) se presenta ahora más bien como un contra-valor que en cuanto tal tenderá a comprometer, a amenazar hasta hacerlas imposibles, otras realidades axiológicamente cargadas que en este caso serán conceptuadas como incompatibles con el ocio. Nos parece evidente que entre otras, la propia salud espiritual de los seres humanos ( esto es, su beatitud eterna post-mortem) constituye un "bien" y un "valor" - y acaso el bien y el valor par excellence- que en determinadas sociedades de 
diferentes estratos históricos puntuaría ciertamente muy alto entre las realidades valiosas a promover.

Es lo cierto sin embargo, que en el horizonte teológico de la ética protestante del trabajo tal y como esta misma fue analizada clásicamente por Max Weber en sus célebres estudios sobre sociología de la religión (Weber, 1983),el ocio, asociado ahora de modo muy próximo a los contra- valores pre o anti-capitalistas de la negligencia profesional, la desidia, la impuntualidad o el abstencionismo festivo contrastarán poderosamente, en cuanto que tales contra-valores, con la probidad profesional de aquellos creyentes reformados que sabían muy bien cómo proveerse en la tierra, de la certeza de la salvación en los cielos. En este sentido, el horizonte soteriológico luterano entendido de este modo empuja por tanto a una valoración hiperbólicamente positiva del negocio ( definido justamente, adviértase esto, como necotium, como la misma negación del ocio) en cuanto que en él pueda advertirse la capacidad de conducir eficazmente a la salvación ultraterrena del hombre. Pero esta valoración representa, obsérvese, al mismo tiempo y en virtud del mismo movimiento una condenación igualmente enérgica, terminante, del ocio como tendencia- inscrita sin duda en el corazón de los hombres pero sólo en tanto este corazón pueda a su vezconceptuarse como corrompido por el pecado- que bloquearía la acción salvífica del trabajo profesional y metodizado.

Nos importa sobremanera comprender bien el siguiente extremo: una tal propensión al activismo profesional intra-terreno que Weber conceptúa como ascesis, terminaría según esta hipótesis por quedar secularizada al través de la formación del capitalismo industrial moderno precisamente en aquellas sociedades más deudatarias del cristianismo reformado en lo referente a su conformación históricoteológica. Cuando estas tendencias a la ascesis profesional, a la valoración hiperbólica del trabajo y a la negación consiguiente del ocio como contra-valor, presentes sin duda en la ética luterana, conozcan una exacerbación verdaderamente límite en el puritanismo de origen calvinista ( Walzer, 1965), el ocio comenzará a entenderse como un resabio satánico a barrenar del dintorno de una república de santos organizada - a la ginebrinanaturellment!- ad maiorem Dei gloriam. Y no se tratará tanto ahora, de contra-distinguir un ocio "valioso" de otro ( esto es: de otro ocio o al menos de otra variedad de ocio) que en cambio no lo fuese, puesto que para empezar es esta misma distinción la que comenzará por desvanecerse por impertinente en el seno mismo de la condenación omnímoda de las actividades de ocio por parte del pensamiento teológico puritano. Simplemente sucede que aquí el mismo "ocio cultural" empezará a verse como un indicio infalible de la condición des-graciadade sus cultivadores puesto que, en efecto, $\dot{\imath}$ qué puede interesar al puritano en su calidad de hombre en gracia de Dios, la misma música de Bach que todavía había podido servir en la 
luterana Leipzig del barroco para acompañar las misas cristianoreformadas del XVII?. Respondemos calvinísticamentepor nuestra cuenta: verdaderamente de muy poco, como no fuese al modo de un pueril entretenimiento ( en sí mismo pecaminoso sin duda) o de una vana delectación estética que en términos agustinianos hubiésemos de tipificar como una auténtica conversio ad creaturam.

Ahora bien, la propia teología moral católica, sin perjuicio de sus cruciales diferencias en este punto respecto del ascetismo intra-terreno protestante, ha conocido desarrollos igualmente refractarios a la consideración del ocio como un fenómeno valioso. En este contexto, por mencionar un caso ejemplar que nos parece suficientemente significativo, en el tratado IX de su Compendio moral salmaticense según la mente del Angélico Doctor de 1805, el carmelita descalzo Marcos de Santa Teresa (Santa Teresa, 1805) sostiene en su discusión del precepto de la limosna que ésta, sin perjuicio de constituir formaliterun acto virtuoso, conduce materialiter en determinadas circunstancias a fomentar el vicio de la ociosidad entre los receptores de la generosidad del donante. Ahora bien, aunque la ociosidad no se conciba como un pecado en sentido propio ( y ello por mucho que ciertas direcciones dentro de la teología moral católica en efecto la conciban así), y desde luego en modo alguno como un pecado mortal, sí que, ciertamente, tenderá a ser percibida como la ocasión virtual de otros muchos pecados, ahora sí, mortales.

Y no se trata sólo de la cristalización de la moral católica en el Compendio salmaticense. Es la entera tradición escolástica por boca de algunas de las figuras más venerables de su centenario recorrido ( Santo Tomás, Antonino, Bernardo de Siena, Cayetano, etc) la que ha insistido de una forma auténticamente enfática en la detestación del pecado mortal de la acidia o "flojera" intelectual y moral condenada con especial contundencia en el Concilio de Trento. En esto repara por ejemplo, con toda claridad Werner Sombart en su clásico estudio El burgués ( Sombart, 1972)razonando de alguna manera contra la consabida pero acaso algo facilona identificación weberiana de la ética protestante con los fermentos iniciales del capitalismo moderno. Sea de ello como sea, es lo cierto que unas tales inclinaciones muchas veces más activistas que meramente contemplativas por parte de la teología moral y de la ética social católica romana han venido conformando los ritmos y los regímenes sociológicos de muchas sociedades políticas en los últimos dos siglos: de la modernización de la Francia post-revolucionaria del XIX y los comienzos del XX (Weber, 1976) a la transformación tecno-científica del paisaje de España a lo largo de su progresiva modernización bajo los auspicios del ideario nacionalcatólico en la segunda mitad del siglo XX ( Camprubí, 2014). 


\section{Del reino ontoteológico de la gracia al reino de la cultura.}

Ahora bien, así las cosas, la cuestión que se abre inmediatamente en el horizonte, resonaría según nos parece de la forma siguiente: ¿̇ cómo entender, en efecto, el tránsito entre dos concepciones del ocio tan diferentes como puedan serlo las que se abren camino denotativamente a través del doble sentido objetivo y subjetivo del genitivo del rótulo titular?. Creemos que en este contexto resulta hacedero dar cuenta inteligiblemente de un tal viraje históricoconceptual mediante el aprovechamiento de la hipótesis medular planteada por el filósofo español Gustavo Bueno en su libro El mito de la cultura ( Bueno, 1996). En esta obra, Bueno lleva adelante una reconstrucción crítica de los orígenes de la idea de Cultura en virtud de la cual la distinción medieval entre un reino sobrenatural de la Gracia y un reino de la Naturaleza- un dilematismo, efectivamente, entre cuyos límites habría quedada encastrada la tradición metafísica de signo ontoteológico propia de la Edad Media- se habría transformado al través del desarrollo doctrinal del idealismo alemán ( Herder, Jacobi, Fichte,Schelling) en una segunda disyunción a la que habrá que reputar en tanto que heredera de aquella: la que separa a la Cultura de la Naturaleza. Y no es ciertamente que el reino de la Gracia pueda a su vez reducirse al de la Cultura por mucho que constituya su embrión ontogenético ( puesto que las premisas ontoteológicas de partida jamás podrían avenirse a semejante sociologismoo etnologismo sin quedar enérgicamente desvirtuadas por ello: efectivamente, nada más herético y absurdo teológicamente que afirmar algo tan trivial antropológicamente como que la religión es cultura ) como tampoco resultara fácilmente practicable la reducción recíproca ( sin pecar en un sobrenaturalismo agustiniano francamente desquiciado según el cual la cultura humana no compareciese más que como un resultado de los dones del espíritu santo). No. Más bien lo que sucede es que el reino moderno ( la Cultura) resultará de una transformación transyectiva del medieval ( la Gracia) en cuya virtud muchos de los rasgos característicos de esta podrán todavía advertirse con absoluta claridad en la fisionomía de la idea de Cultura bien que distorsionados sistemáticamente, es decir, deformados en su geometría.

Y es que, ciertamente, así como la Gracia sobrenatural se entendía a la manera de una emanación sobrenatural que sin necesidad de destruir la Naturaleza ( recuérdese en este punto la vieja conseja tomista: Gratia naturam non tollit...) la perfeccionaba ( ...sed perficit) derramando sobre ella sus abundantes dones, así también la Cultura se propenderá a presuponer ahora, a partir ante todo del despliegue del romanticismo alemán, como sobreañadida a la Naturaleza, sobrepujándola desde luego, sin perjuicio de no destruirla del todo.

Damos por evidente por lo demás que algunas de las funciones más señaladas de la Gracia en sus dimensiones salvíficas ( gracia elevante, 
gracia santificante, gracia medicinal) habrían quedado conservadas, bien que transformativamente, entre los contornos de la nueva idea de Cultura. Lo que sostenemos en este contexto es algo realmente muy simple: la cultura, y muy en particular ni que decir tiene el ocio cultural a la manera de la Gracia soteriológica de la que procedería, también opera elevando, sanando, santificando y salvando a los hombres mediante sus dones más preciosos ( de la contemplación de los ejemplos más refinados y sublimes de la pintura del pre-renacimiento o del informalismo abstracto al disfrute reverencial de los productos más destilados de la ópera italiana o del rock radical vasco). Quien pueda sentirse elevado a la presencia de la cultura por medio del aprovechamiento de tales dones, gozará sin duda de una felicidad en la que en cambio todavía podrá advertirse con toda claridad la cercanía de la vieja visión beatífica (Bueno, 2005)del antiguo régimen ontoteológico de la Gracia.

$Y$, nos preguntamos por nuestra parte, ¿̇ no es acaso este carácter felícitario la verdadera razón por la que el ocio cultural se estima sin duda alguna como valioso?. Obsérvese que aquí no estamos sosteniendo que no lo sea. Lo que señalamos por el contrario es algo diferente, a saber: aunque procedamos dando por supuesto que efectivamente lo es (i.e: que es valioso), este valor no podrá sostenerse salvo petición de principio en su misma condición cultural a no ser que al mismo tiempo demos por descontada una visión soteriológica de la cultura misma. Consideraciones muy análogas se aplicarían aquí al caso del ocio deportivo: no es tanto que el deporte se encarezca en sus mismas virtualidades músculo-esqueléticas o fisiológicas ( pues estas virtualidades, por muy legítimas que puedan ser, carecen evidentemente de toda connotación sublime y aun de cualquier interés fuera del rasante fisiológico o anatómicol cuanto que- se presupone en todo momento-si el ocio deportivo puede postularse como ocio valioso ello se deberá en todo caso al grado en que el deporte mismo sitúa a los hombres en una plataforma trascendental conectada con los valores eternos de la humanidad, del bienestar y de la beatitud. Y no es otro realmente el contenido de la filosofía del olimpismo. (Bueno, 2014).

\section{Conclusiones.}

Concluimos: hemos pretendido medir aquí las diferencias entre dos concepciones del ocio diametralmente opuestas entre sí. Se nos dirá sin duda que ambos marcos, sin perjuicio de las analogías que hemos pretendido encarecer en este trabajo - y que, suponemos, muchos tenderán a contemplar como descabelladas- mantienen alcances muy distintos. Y sin duda es así. Acaso la principal conclusión que nos corresponde extraer en este momento resonaría del modo que sigue: dichas diferencias, que por supuesto damos enteramente por supuestas, 
no se recortarán, sin embargo, tanto a la escala de la distancia que pueda separar una doctrina teológica de otra doctrina científicocategorial. Y ello, puesto que el mismo repertorio léxico, muy abundante por cierto, que ambas concepciones comparten ( felicidad, valor, humanidad, auto-realización, etc, etc) no se mantiene en un plano propiamente positivo. Tal es en efecto nuestro diagnóstico: no se trata si no nos equivocamos de un marco teológico o metafísico para pensar el ocio frente a otro que pudiese eventualmente presentarse como científico. Más bien nos encontramos ante dos genuinas metafísicas del ocio frente a frente.

\section{Referencias:}

Bueno, G, (1996). El mito de la cultura. Ensayo de una filosofía materialista de la cultura. Barcelona: Prensa lbérica.

- (2005). El mito de la felicidad: autoayuda para desengaño de quienes buscan ser felices. Barcelona: Ediciones B.

Pentalfa.

(2014). Ensayo de una definición filosófica de la idea de deporte. Oviedo:

Campubrí, L, (2014).Engineers and theMaking of theFrancoistRegime. CambridgeLondres: MIT Press.

Cuenca, M, (2014). Ocio valioso. Bilbao: Universidad de Deusto.

Goldstein, K. (1934). Der Aufbau des Organismus. Einfühurng in die BiologieunterbesondererBerücksichtigung der Erfahrungen am krankenMenschen. La Haya: Nihjoff.

Harman, R, (1959). La estructura del valor. Fundamentos de axiología científica, México: FCE.

Navajas, A y Balsells, M (2013). "El ocio compartido como mecanismo de resiliencia familiar: perspectiva de los jóvenes.", en Madariaga, J et al ( Eds). La construcción social de la resiliencia, Bilbao: Universidad del País Vasco.

Madrid, C, ( 2010). "Filosofía, Economía y Cambio Climático: un ménage á trois muy productivo", en El Catoblepas n98, pp 15

Maslow, A, (1998). El hombre autorealizado. Hacia una psicología del ser. Barcelona: Kairós.

Scheler, M, ( 1948). Ética, Buenos Aires: Revista de occidente.

Séneca, ( 2010). Sobre la firmeza del sabio, sobre el ocio, sobre la tranquilidad del alma, sobre la brevedad de la vida. Madrid: Alianza editorial.

Sombart, W, (1972). El burgués. Madrid: Alianza editorial.

Weber, E, (1976). PeasantsintoFrenchmen. TheModernization of Rural France 18701014.Standford: StandfordUniversityPress.

Weber, M. (1983). Ensayos sobre sociología de la religión. Madrid: Taurus. 